\title{
DOSSIER
}

\section{SOBRE LA PROPIEDAD COMUNAL DE LOS PUEBLOS. DE LA REFORMA A LA REVOLUCIÓN}

\author{
Emilio Kourí \\ Universidad de Chicago
}

G estudio del pasado agrario fue alguna vez uno de los
grandes ejes de la historiografía mexicana, fuente de grandes obras sobre un país que por siglos $-\mathrm{y}$ hasta hace relativamente poco - fue fundamentalmente agrícola, y en cuya evolución social figuraron de manera prominente las luchas por la propiedad de la tierra. De un tiempo para acá, sin embargo, las investigaciones serias de carácter histórico acerca de cuestiones agrarias han perdido algo de aquella visibilidad o lustre, quizá porque desde hace ya más de medio siglo tanto la población como la producción económica del campo han sido minoritarias y los procesos de urbanización y emigración han avanzado casi sin freno, quizá también por el fin, largamente anunciado, de la reforma agraria de la Revolución, y además porque las modas historiográficas han venido a fijar otros rumbos aparentemente más atractivos y por allí se han encaminado muchos de los

Fecha de recepción: 25 de agosto de 2016

Fecha de aceptación: 12 de septiembre de 2016 
jóvenes que ahora deciden dedicarse al oficio de historiar. Y es que si el devenir del México rural tiene ya poco que ver con los problemas y debates del México contemporáneo, poco habrá de importar entonces - razonarán algunos, de manera equivocada - ponerse a seguir rebuscando entre las olvidadas menudencias de su largo pasado.

A pesar de todo esto, llama la atención que desde hace poco más de dos décadas, y en medio de ese declive de interés historiográfico, se ha comenzado a gestar poquito a poco una revisión significativa de lo que por más de 100 años ha sido la narrativa hegemónica y trama central de la historia agraria del México moderno: la saga de los pueblos que perdieron sus tierras desde la Reforma y durante el porfiriato para luego recuperarlas (en cierto modo) con la Revolución y su reforma agraria. Esta reconsideración crítica es un proceso incipiente, no siempre consciente y todavía muy fragmentario y descoordinado; consiste, en primera instancia, en el descubrimiento - por medio de investigaciones puntuales en archivos locales - de muchas cosas que no se suponía que hubieran pasado y que no parecen en lo esencial excepcionales, sucesos que no cuenta y no es capaz de contar la interpretación que hemos heredado: pueblos que quieren y piden subdividir sus terrenos, indígenas desamortizadores, comuneros acomodados que acaparan las tierras de sus condueños, vecinos que prefieren la pequeña propiedad, especuladores y leguleyos que son hijos del pueblo y trafican con sus tierras, por mencionar sólo algunos.

Si bien esta revisión se encuentra aún en un estado embrionario, ocupada sobre todo en documentar empíricamente nuevas historias locales que socavan la narrativa tradicional por la vía negativa, lo cierto es que ha comenzado 
a abrir caminos analíticos tras los cuales se puede vislumbrar otra manera de entender la historia de la propiedad de los pueblos en la segunda mitad del siglo xix, y en consecuencia también su relación con los procesos de reforma agraria instaurados a raíz de la Revolución. Si el desmoronamiento de la propiedad colectiva de los pueblos - allí donde ocurrió - fue a fin de cuentas producto de procesos sociales mucho más complejos y contradictorios de lo que se ha imaginado, entonces toda esa historia - antes y después de la Revolución - se abre de súbito a lecturas posiblemente muy diferentes. Así, considerado el potencial reinterpretativo de esta revisión en curso, resulta extraordinario, pues lo que plantea - aunque todavía no resulte del todo evidente- es justamente la necesidad de repensar aspectos de la historia social y económica de las relaciones de propiedad en el campo que por mucho tiempo se han dado por resueltos y que ahora resultan simplistas o carentes de sustento.

Este breve ensayo se dedica a explorar algunas de las evidentes fisuras conceptuales que las nuevas investigaciones han puesto de relieve, proponiendo con base en ellas una serie de temas que requieren a futuro mayor reflexión y mejor trabajo de archivo. No se trata simplemente de encontrar otra narrativa histórica unitaria acerca de las tierras de los pueblos para contraponerla a la anterior, pues ya va quedando claro que no habrá tal, sino de identificar con mayor certeza los factores y condiciones que produjeron una evolución muy diversa de la tenencia de la tierra en los territorios de origen comunal, en la cual tanto la identidad de los beneficiarios como la contabilidad de los perjudicados varió según el tiempo y el lugar. Eso sí, para poder 
adentrarse en este tipo de análisis es preciso estar dispuesto a examinar algunos de los fundamentos de los dogmas históricos sobre el pasado agrario que las políticas culturales emanadas de la Revolución lograron inculcar tan eficazmente; al menos entre historiadores (que se dejan guiar por la evidencia) esto no debería ser tan complicado.

No es difícil recapitular la esencia del argumento clásico sobre el desmembramiento de las tierras de los pueblos durante la segunda mitad del siglo xix, no sólo porque generaciones de historiadores lo han dado por cierto, sino porque ha formado parte de la historia patria desde que fue incorporado al texto del artículo 27 de la Constitución de 1917. Los pueblos poseían sus tierras en forma comunal, según les habían sido otorgadas a partir de la conquista española y -al menos en zonas de población indígena - de acuerdo con prácticas y costumbres sociales de raíz precolombina. Se deduce además que este era un sistema íntegro, estable, de buen funcionamiento y con un enorme arraigo social. La gente de los pueblos (¿todos, o casi todos?) querían y defendían la propiedad comunal, pues esta era simultáneamente producto y fuente de su cohesión social e identidad local. Se asume también que el acceso a los beneficios de la propiedad comunal debió haber sido por lo general más o menos equitativo, pues de otro modo no se podría explicar el gran apego que se supone sentían hacía ella los miembros de los pueblos en cuestión. En otras palabras, todos disfrutaban (quizá unos más, otros menos, pero, ¿qué más da?) de los bienes que eran patrimonio de sus corporaciones, y gracias a ello se sentían protegidos. A esta escueta lógica histórica se le sumaron a lo largo del siglo xx una serie de argumentos (primero evolucionistas, luego relativistas 
y más tarde multiculturalistas) que postulaban el carácter constitutivo de la propiedad comunal en las culturas indígenas. Y si el colectivismo era una expresión orgánica de la identidad indígena, entonces no quedaba sino concluir que el comunalismo era la forma autóctona (y por ende más auténtica y armónica) de la propiedad mexicana. ${ }^{1}$

Luego, la narrativa prosigue, al prohibir que las corporaciones (incluyendo a los pueblos) poseyeran bienes raíces de casi todo tipo, la Ley Lerdo de 1856 y la Constitución de 1857 trastocaron la multicentenaria estabilidad del régimen de propiedad comunal, obligando a los pueblos a subdividir y repartir sus tierras. De todo lo anterior se deduce que éstos se opondrían siempre y por principio a las desamortizaciones, y con ello al establecimiento de las pequeñas fincas de propiedad privada individual que los legisladores liberales habían soñado crear. No querían ni les convenían esos repartos, ni a la corporaciones-pueblo ni a sus miembros particulares, y por tanto habrían de resistirse a ellos como y cuanto pudieran. No obstante, y contra esa amplia voluntad popular, la fuerza de los gobiernos (estatales y federales) habría de prevalecer, y poco a poco se fueron desmembrando y privatizando casi en todas partes las vastas propiedades comunales que durante siglos los pueblos habían luchado por conservar. Y no fue sólo que la mera aplicación de las leyes de desamortización privara a los pueblos de sus antiguos patrimonios, lo que ya de por sí sería desastroso, sino que su mala y dolosa aplicación (las frecuentes corruptelas, los engaños y los abusos de los poderosos, casi siempre fuereños) durante los años del porfiriato impidieron que las

${ }^{1}$ Kourí, "Los pueblos y sus tierras”. 
parcelas excomunales quedaran en posesión de los supuestos beneficiarios, los miembros de las extinguidas comunidades. Así, en lugar de procrear un orden rural centrado en pequeñas propiedades con dominio pleno, las desamortizaciones de las tierras de los pueblos sirvieron para ensanchar los dominios de las haciendas, viejas y nuevas, empobreciendo a su paso a todos los demás. Y cuando a todo esto se le sumó el embate privatizador de los terrenos baldíos (jurídicamente públicos y federales) propulsado por los gobiernos de Porfirio Díaz, el panorama resultante fue simplemente devastador. Para 1910, concluye esta narrativa, los habitantes de los pueblos ya casi no tenían tierras propias y las haciendas se habían llenado de peones acasillados, jornaleros y medieros, todo un ejército de miserables cargados de agravios y resentimientos a todas luces muy justos. Lo que se da a entender es que la causa primera de esta gran debacle social fue la legislación desamortizadora, y luego su aplicación, tanto la correcta como la fraudulenta.

De ahí que la revolución popular que estalló en 1910 fuera inevitablemente de raíz agraria, más allá de los conflictos políticos cupulares que le abrieron la puerta, y la facción político militar que salió triunfante se vio finalmente obligada a reconocerlo. Fueron ellos los que entronizaron esta narrativa explicativa del pasado agrario reciente en las nuevas leyes fundamentales de la nación, y sobre esa base se fue armando la enorme reforma agraria que redibujó el orden de la propiedad rural mexicana a lo largo del siglo xx. Si la diagnosis era que el descontento agrario que la Revolución había puesto de manifiesto se había producido como consecuencia del desmembramiento de las tierras comunales de los pueblos, la solución era procurar su reconstitución, por 
restitución o nueva dotación, y así se comenzó a hacer. Poco después, por razones de diversa índole, la reforma derivó en la creación de nuevas comunidades de población dotadas de tierra (ejidos), independientemente de si habían o no tenido alguna vez terrenos en dominio comunal. De esta manera, la reforma agraria de la Revolución se ideó y estructuró, al menos al principio, como un esfuerzo por revertir el daño a los pueblos que según la narrativa histórica habían causado las desatinadas y corrompidas políticas desamortizadoras y privatizadoras del último medio siglo. Así, se asumía no sólo que los efectos de todos aquellos turbulentos cambios en la tenencia de la tierra habían sido deplorables (lo que, de por sí, no era difícil de constatar, cualesquiera hubieran sido sus causas), sino también - y aquí está lo importanteque las causas eran ni más ni menos que las descritas, pues de no ser así el remedio propuesto (la forma de la reforma agraria) no tendría el mismo sentido.

Como las dos caras de Jano, el pasado y el futuro de la propiedad agraria en México se unieron en esta nítida narrativa que parió la Revolución. Afincada en la propia Constitución, guía conceptual de una redistribución de tierras sin precedentes, artículo de fe en la historia patria, esta visión del pasado rural decimonónico (resumida toda en una gran frase de bolsillo, "la cuestión de la tierra") permaneció inmune por mucho tiempo a cualquier examen crítico o profundización, incluso entre aquellos que por diversos motivos se opusieron al avance de la reforma agraria implementada por los gobiernos de la Revolución. Y así, como casi todo lo relacionado con la imagen ortodoxa del porfiriato, el estudio con base en fuentes documentales de las transformaciones en la tenencia de la tierra y las relaciones 
sociales relativas a los pueblos del ancien régime se mantuvo prácticamente congelado hasta hace muy poco.

Por suerte, este panorama ha comenzado a cambiar. Desde hace poco más de tres décadas, han venido produciéndose pequeñas olas de investigaciones disonantes. Vistas en conjunto, todavía no parecen mucho: docenas de ensayos, varias tesis y un puñado de libros. ${ }^{2}$ La mayoría son estrictamente monográficos, estudios de caso con mayor o menor profundidad, y se pueden contar con los dedos los que tienen mayores ambiciones interpretativas; algunos intuyen o hasta dicen que el asunto tiene (o al menos puede tener) gran importancia historiográfica, pero por lo general los textos en cuestión se contentan con describir la novedad de lo que han descubierto. Aun así, esto no es poco.

Hay evidencia - algo fragmentaria e indigesta, pero indiscutible y muy sugerente - de que, lejos de ser armónicas y

${ }^{2}$ La siguiente es una muestra representativa (y no un listado completo): Arrioja, "Entre costumbres"; Birrichaga y Salinas, "Conflicto y aceptación"; СамаCHO, "Desamortización y reforma agraria”; Crespo, "Los pueblos de Morelos": Escobar Ohmstede, Las estructuras agrarias; EscobAR OHMSTEDE y BUTLER, "Introduction"; Escobar Ohmstede y Schryer, "Las sociedades agrarias"; Franco, "La desamortización de bienes"; Franco, La ley y la costumbre; Knowlton, "La división de las tierras"; Kourí, "Los pueblos y sus tierras"; Kourí, Un pueblo dividido; Marino, "La modernidad a juicio: los pueblos de Huixquilucan"; MARIno, "La modernidad a juicio: pleitos por la tierra"; MARINO, "La desamortización de las tierras"; MARINO, "Lecturas posrevolucionarias"; Mendoza, Los bienes de comunidad; Mendoza, Municipios, cofradías y tierras comunales; Menegus, "La venta de parcelas"; Menegus, "Ocoyoacac", Menegus, La Mixteca Baja; Menegus y Cerutti, La desamortización civil; Pérez Montesinos, "Poised to Break"; SÁnchez Rodríguez, "Ixtlán”; SÁnchez Silva, La desamortización civil; SCHENK, "La desamortización”, y SCHENK, "Muchas palabras". 
solidarias, las relaciones sociales y la distribución de derechos de propiedad dentro de los pueblos eran por lo general muy complejas y desiguales, lo que con frecuencia se tradujo en posturas encontradas respecto a la conveniencia de las desamortizaciones; hay evidencia de que no pocos pueblos optaron por impulsar ellos mismos los repartos de sus tierras, cuando así le convino a los intereses de sus facciones dominantes; hay evidencia de que en muchas ocasiones los protagonistas de los repartos (y no sólo sus víctimas) fueron miembros de los pueblos, indígenas o no; hay evidencia de que donde hubo fraude o trampa en la disposición de los terrenos comunales, los protagonistas de tales despojos a menudo fueron también hijos del pueblo (gente del ayuntamiento, vecinos pudientes, etc.), y no únicamente gavilanes fuereños; hay evidencia de que la existencia de derechos de propiedad privados de facto sobre parcelas agrícolas dentro de los territorios nominalmente comunales era ya una costumbre de viejo arraigo en muchos lugares antes de 1856, lo que en tales situaciones vendría a darle un significado diferente a los repartos; hay evidencia también de que los arrendamientos e incluso las ventas de derechos individuales y privados sobre predios de cultivo ya sucedían dentro de las tierras de los pueblos antes de que se decretaran las desamortizaciones; hay evidencia de que a pesar de que con frecuencia hubo irregularidades y arbitrariedades abusivas en los procesos de reparto, éstos sí produjeron, al menos en primera instancia, numerosas pequeñas propiedades (algunas perdurarían, otras no); y hay evidencia también de que ciertos factores económicos (cambios en el valor potencial de la tierra, el surgimiento de nuevos mercados para productos agrícolas, forestales o pecuarios) por lo 
general fueron muy buenos indicadores - mucho mejores que la mera puesta en vigor de leyes y decretos desamortizadores por parte del Estado- del desarrollo oportuno de incentivos (y de presiones, internas y externas) para privatizar la tierra comunal, y que éstos a su vez estuvieron íntimamente ligados a las particularidades de la geografía, la ecología y la demografía de cada lugar. Se sabe ahora muy bien además que - contrario a lo que sentenció la narrativa clásica- muchos pueblos (sobre todo en regiones aisladas del sur) mantuvieron en los hechos sus propiedades comunales a pesar de todos los mandatos de la ley, una realidad inesperada que en su momento la reforma agraria de la Revolución tuvo que reconocer, creando un nuevo estatus jurídico para acomodar dentro de la nueva estructura agraria esos viejos bienes comunales que no se suponía que siguieran existiendo.

Gracias a todas esas investigaciones, ya no se puede afirmar que los pueblos se opusieron a las desamortizaciones de sus tierras siempre y por principio, por el mero hecho de ser corporaciones comunales, y que subdividieron su propiedad sólo porque fueron obligados; si se opusieron, hace falta indagar cómo, cuándo y hasta cuándo, quiénes y por qué. También debe quedar claro que - al menos respecto a la cuestión del manejo y destino de las tierras comunales"el pueblo" nunca tuvo ni actuó con una sola voz, pues consistía en gente con intereses diversos y a veces contradictorios. Dicho de otro modo, cuando se trata de pensar acerca del funcionamiento y evolución (o disolución) de la propiedad comunal desde una perspectiva analítica, "el pueblo" o "la comunidad" son rara vez sujetos útiles, pues son conceptos genéricos que opacan mucho más de lo que revelan. 
Tampoco se puede ya afirmar categóricamente que el desmembramiento de los dominios comunales produjo inmediata, inevitable e invariablemente la concentración de esa tierra en manos de unos pocos. Es aparente que en muchos lugares las tierras excomunales acabaron formando parte de propiedades mayores, pero no queda claro si esto es atribuible directa y únicamente a la conducta de las desamortizaciones per se o a sucesos posteriores de otra índole. Los resultados importan, pero también los procesos y sus cronologías causales. Y si bien la concentración de la propiedad fue a fin de cuentas una de las consecuencias más palpables de las olas de transferencias de la tenencia de la tierra (legítimas o no) que caracterizaron a aquellas décadas, también es aparente la existencia de pequeñas parcelas en dominio pleno surgidas de los repartos comunales. La suya es una historia que queda todavía por contarse. En fin, aunque es evidente que lo que falta por entenderse es aún bastante, estos comienzos son sin duda prometedores.

Es de esperarse que el desarrollo de nuevas investigaciones en archivos vaya encauzando este proceso de repensamiento historiográfico. Por lo pronto, los acercamientos inductivos - por medio de estudios de caso - siguen siendo absolutamente imprescindibles para contrarrestar con la acumulación de evidencia empírica la propensión a restarle importancia a estos descubrimientos disonantes, descartando, simplemente ignorando o - en el mejor de los casosdando por excepcionales (y por tanto intrascendentes) sus conclusiones. Hasta ahora, en pleno siglo xxI, muchas de las narrativas generales producidas por los historiadores continúan reeditando la versión clásica en su esencia, aunque ya 
hay algunas que comienzan tímidamente a matizarla, ${ }^{3}$ pero si las revisiones actuales se extienden y profundizan, llegará el día en que habrá otras historias para contar y mejores explicaciones que dar.

Los tres ensayos incluidos en este dossier son ejemplos recientes, cada cual a su manera, de los caminos que va tomando esta apertura interpretativa. Edgar Mendoza ya ha publicado dos luminosas monografías sobre la evolución de la propiedad comunal en varios pueblos de la Mixteca oaxaqueña. Ahora presenta aquí un texto ampliamente documentado que no sólo rescata del olvido el surgimiento de pequeñas parcelas privadas excomunales en las tierras desamortizadas del pueblo de San Juan Teotihuacán, sino que además muestra que éstas siguieron siendo importantes aún después de la Revolución, en el periodo de la reforma agraria ejidal. Luego, el contundente artículo de Fernando Pérez Montesinos, derivado de su tesis doctoral, ofrece un excelente análisis sinóptico con fuentes de primera mano de los complejos procesos de desamortización dentro y fuera de los pueblos en la meseta purépecha de Michoacán, y contribuye además notablemente al esfuerzo por identificar las bases conceptuales del revisionismo en ciernes, subrayando la injerencia específica de factores dinámicos - geografía, economía, demografía, cronología, leyes - que otras investigaciones anteriores ya han venido destacando. Y por último el incisivo ensayo de Helga Baitenmann, extraído de una extensa monografía de próxima publicación, traza

${ }^{3}$ Compárese, por ejemplo, la Historia general de México: versión 2000 con la Nueva historia general de México de 2010, ambas editadas por El Colegio de México. 
- apoyado en una base documental muy rica - la evolución del papel de los poderes judiciales en la resolución de conflictos relativos a las tierras de los pueblos, desde el siglo XIX hasta la Revolución. Muestra así los orígenes de uno de los aspectos fundamentales de la reforma agraria - la casi total exclusión de los tribunales en los procedimientos de expropiación y dotación que redistribuirían buena parte de la propiedad agraria durante el siglo xx. Es un texto que - al igual que los otros dos - refuerza la importancia de estudiar la historia agraria de antes y después de la Revolución en su conjunto, descubriendo vínculos y continuidades que han sido opacados por la narrativa clásica. ${ }^{4}$

Hay que insistir en la necesidad de producir más investigaciones de este tipo, para enriquecer con ellas un corpus documental que permita trascender el poder ya subliminal de una vieja interpretación de tan profundo arraigo cultural. Con el ánimo de impulsar dicha tarea, pero también porque la mera proliferación de nuevos estudios agrarios desde las desamortizaciones hasta los inicios de la reforma agraria - si bien es necesaria - no será de por sí suficiente para construir un entendimiento - diferente, fidedigno y coherente - de aquellos turbulentos procesos históricos, ofrezco ahora muy brevemente una serie de observaciones - tanto conceptuales como historiográficas - que podrían servir para orientar el desarrollo futuro de esta agenda de investigación y reinterpretación.

\footnotetext{
${ }^{4}$ Mendoza, Los bienes de comunidad; Mendoza, Municipios, cofradias $y$ tierras comunales; Pérez Montesinos, "Poised to Break"; Helga Baitenmann, "Matters of Justice: Agrarian Reform and the Judiciary in Revolutionary Mexico", manuscrito no publicado.
} 
Se le han atribuido a la Ley Lerdo poderes causales extraordinarios, por eso en la vieja bibliografía es el gran parteaguas de la historia agraria del siglo XIx: antes, una cosa, y después, otra muy diferente. No es por casualidad que se centran en ella las dos leyes fundacionales de la reforma agraria de la Revolución: el decreto de 6 de enero de 1915 y el artículo 27 de la Constitución de 1917. Bien o mal aplicada, explican con autoridad ambos textos, la Ley Lerdo le abrió las puertas al despojo de las tierras de los pueblos, y es por tanto de suponerse no sólo que la privatización de la propiedad comunal fuera un fenómeno inexistente antes de 1856, sino además que si la Ley Lerdo no se hubiera promulgado nada de aquello habría sucedido y los terrenos de las corporaciones pueblo se hubieran mantenido intactos. En realidad, la Ley Lerdo explica muy poco acerca de cómo y por qué los pueblos desamortizaron sus tierras (o no), y es un pobrísimo indicador de la cronología de esos repartos. Si se trata de identificar leyes que incidieron en el desarrollo de esos procesos, ya se ha venido reconociendo que las de los estados fueron mucho más relevantes, aunque también hay que cuidarse de no exagerar su propia eficacia. Las leyes meramente imponen reglas (formas, tiempos, etc.), pero si éstas se cumplen o no (y cómo) depende enteramente de otros factores sociales que la legislación es casi siempre incapaz de predecir.

En cuanto a las leyes desamortizadoras de los estados, lo revelador es que en varios casos éstas preceden por décadas a la Ley Lerdo -1826 y abril de 1856 en Veracruz, 1827 y 1851 en Michoacán, por mencionar sólo dos. No se ha investigado todavía qué efectos o reacciones produjeron 
aquellos mandatos tempranos, pero, sin asumir nada, aun si estos fueran nulos o casi nulos, su mera existencia refuerza lo dicho anteriormente. No es buena idea dejarse guiar por la emisión de leyes para estudiar la evolución de la propiedad comunal a lo largo del siglo xIX. Cuando algún día sea posible elaborar una cronología más o menos precisa de la subdivisión de las tierras de los pueblos, se verá claramente - por la diversidad y complejidad resultantes - que no hay razón analítica para seguir dándole a 1856 el estatus de progenitor que tuvo en el siglo xx. Y si las leyes no son el eje principal de esta historia, no queda sino buscarlo en otras partes.

\section{LA PROPIEDAD COMUNAL DE LOS PUEBLOS}

ANTES DE LAS DESAMORTIZACIONES

A pesar de lo que a menudo se imagina o se supone, no hay nada que indique que la distribución normal de los derechos de acceso a la propiedad de las comunidades antes de las desamortizaciones era equitativa y consensuada, sino al contrario. Hay una imagen idealizada a priori del carácter de la vida comunitaria en la que destacan una serie de enraizadas virtudes que habrían de explicar el buen funcionamiento y la larga estabilidad de estas corporaciones-pueblo: la cohesión social, la solidaridad local y la economía moral en el acceso a los bienes colectivos. Según este preconcepto, la organización incluyente - y en el fondo armónica - del uso repartido de la tierra comunal sería la expresión práctica más acabada de aquellos valores culturales.

Se puede argumentar (con evidencia) que en algunos o quizá en muchos casos tales virtudes sí incidieron en ciertos 
aspectos de la vida política y religiosa de esas comunidades, pero la asignación de derechos de uso sobre la propiedad raíz fue casi siempre un asunto diferente, y no un reflejo terrenal de aquel esprit de corps ideal. A modo de generalización puede decirse que la distribución de tierras (llamadas "de repartimiento") para el cultivo entre individuos y familias de la comunidad fue casi siempre desigual, y a veces notablemente inequitativa. Unos miembros tenían más (o mejores), otros menos, y algunos - sobre todo en situaciones de presión demográfica - nada o casi nada. Estos últimos trabajaban en haciendas o ranchos aledaños (o para otros comuneros), rentaban parcelas sobre las cuales ejercían su derecho otros vecinos, o simplemente se iban. La porción de las tierras comunales dedicada a financiar el gasto de los ayuntamientos (los "propios") ordinariamente se rentaba - a hacendados, pero también a miembros pudientes o influyentes del común-, aun cuando hubiera hijos del pueblo sin parcelas propias. En otras palabras, en realidad ser hijo del pueblo - y por tanto miembro de la comunidad - no garantizaba de por sí ni siquiera el presunto derecho a tener acceso a un pedazo cultivable del patrimonio colectivo, y mucho menos un repartimiento más o menos equitativo de tales derechos. Es cierto que la historia de cada pueblo está llena de particularidades, como también es cierto que las relaciones sociales en torno de la propiedad cambian con el tiempo, la demografía y el contexto económico, pero ése había sido, grosso modo, el carácter estructural de la relación entre los miembros de una comunidad y los terrenos de su corporación desde mucho antes de que se les abriera un camino jurídico a las desamortizaciones civiles. Aun en pueblos relativamente pobres con cierta densidad 
poblacional se podían observar estas jerarquías en el acceso diferencial a la tierra.

Una zona de excepción - cuando la había - era típicamente el ejido del pueblo, la porción de tierras no agrícolas y de montes destinada al pastoreo, al corte de madera y a la recolección de leña y de diversos productos silvestres. Allí los derechos de uso fueron más genuinamente colectivos y quizá también equitativos, en parte por la inviabilidad - tanto física como económica - de parcelar y restringir el acceso a ellos. La Ley Lerdo exceptuó a los ejidos de las desamortizaciones, y en zonas con un alto índice de repartos fueron esas las propiedades que por su peculiar ecología mantuvieron por más tiempo el estado comunal, aunque en aquellos lugares donde el desarrollo de nuevos mercados (sobre todo el maderero - para papel, durmientes, etc.) revaloró esas tierras, muchos ejidos acabaron también siendo privatizados. Una de las razones por la cual la institución creada en la Revolución para devolver o dotarle de tierras a los pueblos fue llamada "ejido" - a pesar de que en un principio las tierras que lo constituyeron eran “de repartimiento", para la agricultura, y por tanto no ejidales en el sentido original - fue la asociación entre la palabra "ejido" y la vieja identidad comunal de los pueblos, no sólo porque los ejidos habían sido la parte de aquellas extintas propiedades designada precisamente para el uso y beneficio de toda la colectividad, sino además porque en la segunda mitad del porfiriato la mayoría de las pocas propiedades comunales que todavía existían en el centro de México eran ejidos, y de ahí surgió el neologismo que convirtió al término "ejido" en sinónimo vía sinécdoque de todas las tierras de los pueblos, incluso las agrícolas. Pero más allá de 
ese curioso malentendido y de sus repercusiones históricas, queda bastante claro que durante el régimen de propiedad comunal una cosa fueron las prácticas colectivistas respecto al uso de los ejidos y otra muy diferente la distribución de los derechos dentro de las tierras de repartimiento.

En muchos pueblos, la renta, hipoteca e incluso venta de parcelas comunales de repartimiento - con frecuencia sólo dentro de la propia comunidad, pero no siempre - eran una faceta normal de la organización de las relaciones sociales de propiedad desde al menos el siglo XviII, si no antes. Esas transacciones fueron probablemente uno de los mecanismos que acentuaron la desigualdad en el acceso a la tierra. Es muy difícil - quizá imposible - reconstruir el desarrollo y la evolución de este conjunto de operaciones económicas ligadas a la tierra comunal, pero en las fuentes hay señales abundantes de su larga existencia. Aunado esto al hecho de que la posesión de derechos sobre parcelas de tierra se podía heredar, lo que todo esto describe es una especie de sistemas consuetudinarios de derechos privados de facto sobre terrenos que formalmente pertenecían a la corporación del pueblo. Se trata de prácticas o costumbres complejas, poco estudiadas y seguramente variables (temporal y espacialmente), mas no hay duda de que en muchos lugares así funcionaba y se regulaba la distribución de las tierras comunales de labor. No es ésta la imagen que se encuentra comúnmente en la bibliografía acerca de los pueblos y sus tierras antes de las desamortizaciones, pero si se quieren entender a cabalidad los cambios en el régimen de propiedad rural durante la segunda mitad del siglo XIX, será preciso comenzar a prestarle mayor atención conceptual -y en los archivos - a estas enterradas dinámicas sociales. 
Si en efecto dentro de los pueblos operaban sistemas consuetudinarios de derechos de propiedad más o menos privados (con varios grados de autonomía o restricción), entonces el arribo de las leyes de subdivisión y reparto - federales o estatales - adquiere un significado analítico muy diferente y sumamente interesante, pues visto de esta forma resulta evidente que aquellos mandatos habrían de suscitar entre los miembros de las comunidades reacciones y expectativas no uniformes sino muy diversas, según las condiciones económicas locales, la posición social y agraria de cada persona o familia, y las reglas para los repartos especificadas en cada una de las leyes en cuestión. Si convenía oponerse o no, y por qué motivos, dependería en cualquier caso de cómo se configuraran todos esos detalles cruciales, y no de un rechazo genérico a la mera idea del reparto, pues la mayoría de las tierras comunales ya estaban de hecho repartidas (desigualmente), aunque esto fuera sólo de acuerdo con los poderes jurisdiccionales de las propias corporaciones. ¿Quiénes controlarían los potenciales repartos, quiénes se beneficiarían o perjudicarían, qué pasaría con la distribución actual de las tierras comunales, cómo afectaría el cambio jurídico de la propiedad las facultades de los gobiernos locales? Esas serían las cuestiones (coyunturales y mutables) que incidirían en la postura asumida por cada cual, al menos entre los bien enterados. Para algunos la perspectiva de una desamortización constituyó una amenaza a sus intereses (individuales o colectivos), mientras que para otros representó una oportunidad para mejorar o consolidar su situación, o incluso, por qué no, ambas cosas en diferentes momentos y circunstancias. No se trata con todo esto de minimizar la trascendencia de las desamortizaciones, sino de precisar el 
contexto socioeconómico en que se presentó la posibilidad de subdividir la tierra en dominio pleno.

Es así, en pocas palabras, como se deben pensar los procesos de desamortización dentro de los pueblos. Y fue allí, en primera instancia, donde se fijaron las posturas más determinantes relativas a su tramitación, pues en el ámbito local el poder del Estado era por lo general débil y difuso. Hay también, claro está, toda una serie de actores externos por considerar, pero esos son ya bien conocidos. Por lo pronto, lo que toca enfatizar aquí es que al reenfocar el viejo asunto de las tierras de los pueblos a través de este lente analítico se advierte todo un nuevo horizonte de investigaciones e interpretaciones. En lo que respecta al repartimiento de la propiedad comunal, los miembros de los pueblos no tenían una sola voz, aunque a veces así pareciera, porque en el fondo sus intereses no sólo no eran siempre los mismos, sino que podían ser contradictorios. Con las llamadas a la desamortización, esas fisuras se pondrían de manifiesto.

\section{CORPORACIONES POLÍTICAS}

\section{Y TIERRAS COMUNALES}

Una de las razones por las cuales este acercamiento a la propiedad comunal no ha recibido todavía la atención que requiere tiene que ver con que se ha confundido el carácter de las prácticas políticas de los pueblos hacia el exterior con el de su organización social interna (incluyendo el uso de las tierras), asumiendo que ambos tendrían que reflejar necesariamente las mismas cualidades colectivas, cuando en realidad lo uno podía ser (y por lo general era) relativamente independiente de lo otro. Si hay un tema dominante 
en la historiografía acerca de los pueblos coloniales y decimonónicos es sin duda alguna el de las luchas por múltiples vías para defender los derechos y el patrimonio de sus corporaciones, tanto de la rapacidad de hacendados colindantes como de las pretensiones de autoridades gubernamentales superiores de toda índole. Es una literatura madura y abundante, rica en documentación y detalle, amplia en su cobertura geográfica y cronológica y además marcada por un buen número de obras sobresalientes. Allí se estudian, entre muchas otras cosas, los constantes esfuerzos realizados - primero por los cabildos de indios y luego por los ayuntamientos - por preservar (y a veces extender) los diversos derechos de autogobierno correspondientes a su categoría política, entre los cuales uno fundamental era el dominio sobre la propiedad de sus tierras comunales. El pueblo, ya se sabe, era una gente, un gobierno y un territorio, y defender ante el enemigo externo la integridad de ese espacio fue a menudo no sólo una de sus mayores prioridades, sino también una importante fuente de cohesión política.

Al igual que la veneración de sus santos o de la Virgen - con sus calendarios, preparaciones, rituales y fiestasservía para fomentar, afirmar y expresar la identidad particular de cada pueblo (vis à vis los demás) más allá de cualquier distinción de cargo o estatus social, los conflictos con colindantes $\mathrm{u}$ otros pretendientes sobre linderos, títulos o derechos de tierra y agua fungieron como llamados - por lo general exitosos - a manifestar públicamente la unidad de la comunidad y la solidaridad de todos sus miembros, dejando a un lado - de cara al árbitro externo y al adversario- sus diferencias, al menos temporalmente. Algo parecido se puede decir acerca de las protestas contra el abuso de 
poder por parte de autoridades externas. Por eso no es sorprendente que en peticiones, memoriales, denuncias, declaraciones y demás documentos de carácter litigioso o judicial se encuentre al pueblo - la corporación de poblaciónhablando con una sola voz, la de la voluntad popular indivisa que clama justicia y protección. Es un poco la versión indiana de Fuenteovejuna: el pueblo son todos y todos son uno. No se trata aquí de restarle veracidad o justificación a esas expresiones, sino simplemente de precisar el contexto específico en que se producen.

De tales manifestaciones y de otras formas más directas de acción colectiva - protestas, disturbios, motines, ataques, invasiones, etc. - se desprende la imagen (que se recoge en la literatura histórica) de los pueblos como asociaciones políticas más o menos cohesivas y solidarias, comunidades en la acepción más directa de la palabra, al menos a la hora de defenderse. Y respecto a la manera en que estas corporaciones políticas afrontaron todas aquellas amenazas externas, no cabe duda de que hay en esa imagen bastante de cierto. Sin esas exhibiciones de firmeza y pertinacia colectivas, muchos pueblos no habrían logrado sobrevivir. Hay quienes han querido interpretar tal cohesión como una expresión natural de los valores esenciales e inmutables heredados de las culturas indígenas precolombinas, pero más vale dejar a un lado esa quimera. No hace falta apelar a ningún tipo de ontología para entender por qué los pueblos, cual entes políticos, habrían adoptado consensualmente esas posturas: proteger las autonomías locales y la integridad de la propiedad comunal en su conjunto eran cuestiones sobre las cuales todos - o casi todos - podían ponerse de acuerdo. 
El problema surge cuando se da por sentado que esas demostraciones de cohesión política con miras al exterior eran invariablemente el reflejo o corolario de una solidaridad más amplia en el tenor de las relaciones sociales dentro de las comunidades, la cual seguramente se pondría (o se debería poner) de manifiesto en la distribución de derechos sobre la tierra comunal. Y si tal era el caso, entonces no había necesidad de abordar ese asunto en mucho detalle, lo que además habría sido trabajoso. No hay que negar la importancia que pueda haber tenido la solidaridad en muchos aspectos de la vida pueblerina para darse cuenta de que esta inferencia es un non sequitur, de que una cosa no depende de la otra. Y como se ha dicho, no hay evidencia de que la distribución del acceso a los bienes raíces de propiedad comunal haya sido equitativa o consensual, con la excepción quizá de los ejidos. La unidad política del pueblo en momentos de conflicto (o en otras dimensiones, v.g. la religiosa) no implica ni requiere ningún tipo particular de arreglo respecto a las tierras de repartimiento, del mismo modo que un reparto sesgado de los derechos de propiedad no impide concertar acciones colectivas y unitarias en otros ámbitos. Tal disociación - entre los intereses particulares y los comunes - debió ser algo ordinario en aquellas épocas, como lo sigue siendo en la nuestra. A algunos les parecerá contradictorio, pero no hay incompatibilidad real: pueblos muy desiguales en su perfil económico que presentan un frente común cuando se trata de defender lo que se entiende como propio, aun si sobre el terreno mucho de aquello no es precisamente de todos. 
POR UNA SOCIOLOGÍA DE LOS PUEBLOS DECIMONÓNICOS

Para poder acercarse a las dinámicas sociales relativas al uso y distribución de las tierras comunales en los pueblos hace falta tener al menos cierta idea, por decirlo de manera simple, de los diferentes tipos de vínculos que los vecinos tenían con el aprovechamiento de la tierra, o sea, de las relaciones sociales de propiedad. Es una cuestión empírica y cambiante, en cada pueblo o región, que no se puede estudiar o entender sin poner de por medio algunos conceptos organizativos: por ejemplo, quiénes tenían más tierra, quiénes menos y quiénes no; quiénes rentaban o tenían acuerdos de aparcería; quiénes quedaban amparados por las redes familiares de derechos y quiénes no; quiénes tenían que trabajar fuera del pueblo, etc. Se trata en efecto de elaborar una serie de categorías sociológicas ex profeso que permita distinguir las diversas facultades de acceso a la propiedad agrícola nominalmente comunal, para de ese modo poder retratar, aunque sea en daguerrotipo, la estructura agraria dentro de los pueblos. Tales distinciones no tienen que ser enormes para haber sido significativas, pues la inequidad siempre es relativa, y la terminología empleada para describirlas puede corresponder a los usos locales, siempre muy reveladores, o en su defecto ser impuesta por los historiadores con fines analíticos, según venga al caso. Lo importante a fin de cuentas es contar con algunas herramientas para captar la segmentación del régimen interior de propiedad en los pueblos y poder luego desagregar su relación con el desenvolvimiento de los procedimientos desamortizadores.

Esta es una tarea que se encuentra apenas en su infancia, a pesar de que en los archivos abunden las pistas. Las 
razones son muchas, entre ellas los prejuicios y el ofuscamiento ya mencionados acerca de la naturaleza del ordenamiento social de la propiedad comunal en las corporaciones-pueblo, los cuales han hecho parecer que estas líneas de investigación sean insignificantes e improductivas. Además, contribuye de manera notable a esa ceguera el término que habitualmente se ha utilizado y se sigue utilizando para describir y categorizar a los habitantes de estos pueblos: campesinos. Esta es una palabra que prácticamente no fue utilizada en México antes del siglo xx: por lo general no habían “campesinos” ni en las leyes ni en los documentos oficiales o en la prensa antes de la Revolución; tampoco en los escritos provenientes del campo mismo, en los cuales se nombran vecinos, hijos del pueblo, labradores, naturales, indios, etc., pero nunca campesinos. Sin embargo, los textos académicos y populares, producidos a lo largo del siglo xx acerca del mundo rural en el siglo xix, se refieren comúnmente y con gran naturalidad a "los campesinos" de aquellos tiempos, con todo lo que eso implica. El anacronismo, claro está, no es de por sí un defecto, pues es normal que las categorías y las terminologías de análisis cambien con las épocas. El problema es que para comprender la historia rural de México en el siglo XIX (al menos) el concepto de “campesino" es una herramienta no sólo pobre sino incluso contraproducente.

En México se comenzó a hablar (y escribir) sistemáticamente de los “campesinos” a partir de 1915-1920 y sobre todo durante la década de 1930, y fue en aquellos años que se forjó toda una identidad social alrededor de esa palabra. ${ }^{5}$

5 Véase, por ejemplo, Boyer, Becoming Campesinos, aunque la interpretación allí propuesta es diferente. 
La notable y constante participación armada de mucha gente del campo durante los años de revolución había obligado al nuevo régimen a abrirles un espacio político que no habían tenido antes, y la noción de un "campesinado" como sujeto colectivo sirvió para englobar sus muy diversas demandas e intentar darles una sola forma retórica e institucional. Era una nueva categoría descriptiva e identificativa, elástica y aglutinadora, que aspiraba, por razones políticas, a incluir a casi todos los habitantes del campo, dejando fuera prácticamente sólo a los grandes propietarios. Fruto de variegadas inspiraciones tanto anarquistas como soviéticas, la concepción de "los campesinos" sería deliberadamente homogeneizadora y armónica: una masa de gente rural con intereses y características fundamentalmente similares y con una misma meta, que era tener tierra. Era una idea que por su abarcadora sencillez ofrecía notables ventajas dentro del ámbito político; por un lado, se empalmaba bien con la incipiente lógica clientelar y corporativista de las coaliciones gubernamentales posrevolucionarias, y por otro lado, apelaba también a los intereses de los pertinaces impulsores de la creciente reforma agraria ejidal (tanto peticionarios ordinarios como líderes agrarios), pues al decretarse en el imaginario la paridad sustantiva de todos aquellos llamados "campesinos" se ampliaba de forma considerable el número (y la clase) de gente con derecho a juntarse para solicitar dotaciones de tierra. En fin, puede decirse entonces que "el campesinado" nació en México al amparo de la Revolución y de la mano de la reforma agraria. Pero lo que comenzó (y se enraizó) como una categoría con funciones políticas pronto se quiso convertir en un instrumento de análisis social e histórico, y así empezaron a aparecer campesinos en relatos sobre tiempos y lugares anteriores. 
En buena parte de los estudios acerca de los pueblos en el siglo XIX - escritos casi todos a lo largo del siglo xx - opera más o menos explícitamente la noción de que sus habitantes eran, con raras excepciones, campesinos. Y si no campesinos, entonces “indios" o "indígenas", categorías ambas igualmente niveladoras y cohesivas, aunque con una etiología más explícitamente culturalista. El problema radica en que la homogeneización inherente en la idea de un campesinado - y hablar luego de campesinos "ricos" o "pobres", cuando las diferencias no se pueden ignorar, no es sino reconocer la insuficiencia analítica del concepto - borra el tipo de distinciones socioeconómicas que habría que tomar en cuenta para darle un sentido más claro a los procesos desamortizadores y a sus diversas secuelas en vísperas de la Revolución.

Disponer de una sociología un poco más fina y puntual, aunque sea por lo pronto de bolsillo, facilitará nuevas lecturas de las coyunturas que propiciaron (o no) las subdivisiones de la propiedad de los pueblos, tomando en cuenta no sólo la disgregación de intereses locales - internos y externos - en relación con el fondo y la forma de los repartos, sino también el valor actual y potencial de los terrenos en cuestión, según la condición geográfica, demográfica y económica de cada lugar (caminos, ferrocarriles, acceso al agua, comercialización agrícola, pecuaria y forestal, disponibilidad de mano de obra y de trabajo asalariado, acasillado o enganchado, etc.). Sólo así podrá entenderse qué fue lo que pasó, cuándo y por qué. Vale la pena recalcar, al calibrar la importancia de este proceder analítico e interpretativo, que las leyes estatales de desamortización que regularon la subdivisión de la propiedad comunal civil por lo general 
estipulaban - contrario a la Ley Lerdo federal- que el reparto se hiciera en partes iguales, sin considerar la distribución de derechos y parcelas ex ante, la cual de hecho era desigual. Ahí se encuentra una de las claves para entender por qué unos se opondrían al fraccionamiento y otros no, por qué los procesos de deslinde y asignación de parcelas serían con frecuencia tan contenciosos y propicios al amaño, y por qué, entre otras razones, en muchos casos los notables locales habrían preferido en primera instancia tratar de que no se hiciera nada. Pero para poder acceder a todo ese universo social de consideraciones coyunturales estratégicas - defensivas u oportunistas - dentro de los pueblos hay que saber un poco más quién era quién, y no únicamente que eran "campesinos" o "indios".

\section{LAS PEQUEÑAS PROPIEDADES EXCOMUNALES}

Ya se ha dicho que los fraccionamientos de las tierras comunales parecen haber producido numerosas parcelas individuales, al menos en un inicio. Toca entonces rescatar en los registros esas pequeñas propiedades excomunales de las que casi no hay noticia en las narrativas históricas tradicionales, pues se suponía que no existieron o que fueron efímeras. No es una labor difícil. Hay evidencia de que en varias regiones buen número de esos predios privados - algunos de los cuales fueron rebautizados como "ranchos" - perduraron hasta el siglo xx y formaron parte integral del panorama rural durante las décadas de reforma agraria. Pero es muy probable también que muchos otros se hayan perdido - con o sin trampa- y fueran absorbidos por propiedades mayores en expansión, haciendas 
viejas o de nueva creación. Mientras no haya más investigación al respecto será muy difícil formar una idea más clara del balance de estos procesos y de sus variaciones temporales o regionales, pero por lo pronto cabe resaltar el hecho de que uno de los resultados de las desamortizaciones sí fue la creación de pequeñas propiedades privadas, y no sólo pasajeramente. Cuántas, dónde, para quién y por cuánto tiempo es lo que aún resta averiguar.

No se trata aquí de negar que, grosso modo, en el porfiriato se haya producido a fin de cuentas una notable concentración de la propiedad rural, sino de entender dónde (y dónde no), cuándo y exactamente cómo, reconociendo que si bien muchos pueblos se quedaron sin tierras propias, eso no quiere decir que todos sus habitantes hayan sufrido el mismo destino. Con frecuencia se tiene la impresión, al leer mucho de lo que se ha escrito acerca de la cuestión de la tierra en el porfiriato y sobre los motivos agrarios de la Revolución, que las desamortizaciones de los pueblos y los deslindes de los baldíos no hicieron otra cosa que alimentar directa e inevitablemente el voraz expansionismo de las haciendas, creando a pesar de las resistencias - y casi sin mediación o interludio alguno - un mundo rural bipolar que la Revolución vendría a reventar. Esta visión puede haber valido como estandarte de guerra o arenga insurreccional contra el antiguo régimen, pero en realidad la transformación de la tenencia de la tierra durante el porfiriato fue bastante más compleja, multiforme, imprevisible y gradual de lo que se ha querido imaginar, con una gama de protagonistas - pequeños y grandes - tan diversa que no es posible encasillarla dentro de una narrativa maniquea. 
Rastrear la historia de las parcelas privadas con dominio pleno nacidas de las desamortizaciones en los pueblos es, entre otros, un buen punto de partida para precisar las causas y los medios por los cuales se reestructuró (y concentró) la propiedad territorial en aquellos lugares donde se extinguió el régimen comunitario. Lo importante aquí es identificar secuencias en la traslación del dominio para formar con base en ellas una idea más clara del tipo de prácticas $-\mathrm{y}$ razones - que incidieron en la evolución de la tenencia después de las desamortizaciones, y qué pautas (si alguna) exhibieron éstas. Son muchos los posibles factores a considerar: el peso de las inesperadas cargas fiscales y administrativas impuestas sobre las nuevas parcelas privadas; el endeudamiento por hipoteca y otros medios; las ventas directas, con o sin transparencia; las vicisitudes relativas a la herencia; la usurpación del dominio legal por medio del robo, extravío o desvío de los títulos de propiedad; timos y fraudes de todo tipo; los abusos del poder público y privado, etc. Hay también que considerar que algunos repartos hayan excluido - con la connivencia de las autoridades del pueblo- a vecinos con derechos, privándolos de las parcelas que les correspondían.

En cualquier caso, conviene prestarle particular atención a los beneficiarios de las traslaciones (legítimas o no) a lo largo de dichas secuencias. Una cosa es encontrar, por ejemplo, que un excomunero pudiente o influyente fue adquiriendo - por las buenas o por las malas - cierto número de parcelas que años después vendió (o perdió) en favor de un hacendado, y otra descubrir que el hacendado se las quitó o compró de entrada directamente a los dueños originales. El resultado final puede ser el mismo, pero en términos de 
la historia social de la propiedad son dos vías con significados y protagonistas muy diferentes. No basta entonces con fijarse sólo en los dos polos (el principio y el final) de la gran transformación del orden territorial durante las décadas anteriores a la Revolución, sobre todo cuando la sinopsis que hoy puede ofrecerse de estos polos es mucho menos nítida de lo que se había supuesto; hay que enfocarse por fin en los procesos (a lo largo de más de medio siglo), pues de allí saldrán mejores explicaciones y una visión de conjunto más fidedigna.

Una idea que desde mucho antes de la Revolución ha estado íntimamente vinculada con el tema de las desamortizaciones de las tierras de los pueblos y sus consecuencias sociales es la del despojo y la injusticia: que el fraccionamiento de la propiedad comunal atropelló los derechos de mucha gente de pueblo, desposeyéndola de su patrimonio histórico y sumiéndola en la pobreza y el desamparo. Nada de lo que aquí se ha expresado va en menoscabo de esa idea general, sino al contrario, pues precisar no es menguar, sino aclarar; quiénes despojaron y abusaron, cómo, cuándo, a costa de quiénes y por qué. Eso sí, el asunto es sin duda más gris y complicado de lo que se ha querido contar. Y el examen pormenorizado de los procesos de reparto y del destino de las pequeñas propiedades que éstos generaron es precisamente uno de los hilos de Ariadna que conduce a la salida de estos opacos laberintos.

EL SIGLO XIX Y LA REFORMA AGRARIA EJIDAL

Basta con lo que ya se ha dicho para comprender por qué las repercusiones analíticas de repensar la historia de la 
propiedad comunal en la segunda mitad del siglo xIX no terminan con el alba de la Revolución. La reforma agraria que nació en 1915 y 1917 se fundó explícitamente en una idea muy firme de cómo y por qué los pueblos habían perdido sus tierras, y de ahí surge la vocación restituidora y colectivista que le vino a dar forma en sus comienzos. Y si bien es cierto que los orígenes del ejido como institución no determinan su destino (o su importancia), si la historia que la precede - y que guía su formación - resulta ser otra, cambia también el significado social de los repartos ejidales, al menos en su primera época.

La gente que en un inicio pidió y recibió ejidos para sus pueblos (o rancherías, congregaciones, etc.) tenía ya una historia (la de sus propiedades en las décadas prerrevolucionarias), y ésta no era necesariamente la que aparece - porque así se tenía que contar - en los documentos requeridos para recibir restituciones (o dotaciones) de tierra. En muchos casos las viejas diferenciaciones sociales no habían desaparecido, aunque todos fueran ahora "campesinos" por igual ante el Estado y las nuevas organizaciones agrarias. ¿Quiénes organizaron en la localidad la petición de ejidos, y quiénes fueron beneficiados (o excluidos) en el reparto? La pregunta no es retórica ni frívola: es bien sabido que el acaparamiento de parcelas ejidales y el manejo autoritario de la vida ejidal fueron problemas que surgieron en algunos casos (y no pocos) desde un principio, y llama la atención la posibilidad de que éstos reprodujeran de algún modo dinámicas sociales que ya se habían conocido en esos pueblos. Serían éstas en efecto restauraciones del pasado rural comunitario, pero no precisamente las que la reforma agraria de la Revolución imaginaba promover. ¿Y qué de los pequeños 
propietarios excomunales que sobrevivieron al porfiriato, qué pasó con ellos? La lista de nuevos interrogantes podría continuar: reescribir el pasado desestabiliza todo lo que le sigue, y más cuando éste ha sido concebido no sólo como simple preludio, sino como explicación y justificación.

Ojalá que los historiadores jóvenes se animen a acercarse a algunas de estas ideas y las pongan a prueba en sus investigaciones. Se ha comenzado lentamente a reabrir la historiografía agraria del México moderno, y serán ellos los que podrán escribirle un nuevo capítulo.

\section{REFERENCIAS}

Arrioja Díaz Viruell, Luis Alberto

"Entre costumbres y leyes: las tierras de común repartimiento en una región indígena de México, 1742-1856", en Letras Históricas, 10 (2014), pp. 39-75.

Birrichaga, Diana y Carmen Salinas Sandoval

"Conflicto y aceptación ante el liberalismo. Los pueblos del Estado de México, 1856-1876", en Escobar Ohmstede (coord.), 2007, pp. 207-252.

BOyer, Christopher

Becoming Campesinos: Politics, Identity, and Agrarian Struggle in Postrevolutionary Michoacán, 1920-1935, Stanford, Stanford University Press, 2013.

Camacho Pichardo, Gloria

"Desamortización y reforma agraria en Ocoyoacac y Lerma", en Escobar Ohmstede, Sánchez Rodríguez y Gutiérrez Rivas (eds.), 2008, pp. 287-310. 
Carrasco, Pedro (coord.)

La sociedad indígena en el centro y occidente de México, México, El Colegio de México, 1986.

Crespo, Horacio

"Los pueblos de Morelos. La comunidad agraria, la desamortización liberal en Morelos y una fuente para el estudio de la diferencia social campesina", en Espejel López (coord.), 2000, pp. 57-120.

Escobar Ohmstede, Antonio

Las estructuras agrarias. Pueblos de indios y propiedades privadas, México, Nostra Ediciones, 2010.

Escobar Ohmstede, Antonio (coord.)

Los pueblos indios en los tiempos de Juárez, México, Universidad Autónoma "Benito Juárez" de Oaxaca, Universidad Autónoma Metropolitana, 2007.

Escobar Ohmstede, Antonio y Frans J. Schryer

"Las sociedades agrarias en el norte de Hidalgo, 1856-1900", en Mexican Studies/Estudios Mexicanos, xviII:1 (1992), pp. $1-21$.

Escobar Ohmstede, Antonio, Martín Sánchez Rodríguez y Ana

María Gutiérrez Rivas (eds.)

Agua y tierra en México en el siglo XIX y XX, México, El Colegio de Michoacán, El Colegio de San Luis, 2008, vol. 1.

Escobar Ohmstede, Antonio y Matthew Butler

"Introduction: Transition and Closures in Nineteenth and Twentieth-Century Mexican Agrarian History", en Escobar Ohmstede y Butlen (eds.), 2013, pp. 33-76.

Escobar Ohmstede, Antonio y Matthew Butler (eds.)

Mexico in Transition: New Perspectives on Mexican Agrarian History, Nineteenth and Twentieth Centuries/ México 
$y$ sus transiciones: reconsideraciones sobre la historia agraria mexicana, siglos XIX Y XX México, Centro de Investigaciones y Estudios Superiores en Antropología Social, Llilas Benson, 2013.

ESPEjel López, Laura

Estudios sobre el zapatismo, México, Instituto Nacional de Antropología e Historia, 2000.

Falcón, Romana (ed.)

Culturas de pobreza y resistencia. Estudios de marginados, proscritos y descontentos. México, 1806-1910, México, El Colegio de México, Universidad Autónoma de Querétaro, 2005.

Franco Mendoza, Moisés

"La desamortización de bienes de comunidades indígenas en Michoacán”, en CARrasco (coord.), 1986, pp. 169-188.

La ley y la costumbre en la Cañada de los Once Pueblos, Zamora, El Colegio de Michoacán, 1997.

Historia general

Historia general de México: versión 2000, México, El Colegio de México, 2000.

KnowLton, Robert J.

"La división de las tierras de los pueblos durante el siglo XIx: el caso de Michoacán", en Historia Mexicana, xL:1 (157) (jul.sep. 1990), pp. 3-25.

Kourí, Emilio

"Los pueblos y sus tierras en el México porfiriano": un legado inexplorado de Andrés Molina Enríquez", en Kourí (coord.), 2009, pp. 253-330.

Un pueblo dividido. Comercio, propiedad y comunidad en Papantla, México, México, Fondo de Cultura Económica, El Colegio de México, 2013. 
Kourí, Emilio (coord.)

En busca de Molina Enríquez. Cien años de Los grandes problemas nacionales, México, El Colegio de México, Centro Katz-The University of Chicago, 2009.

Luna Argudín, María y María José Rhi Sausi (coords.)

Repensar el siglo XIX. Miradas historiográficas desde el siglo $X X$, México, Fondo de Cultura Económica, Consejo Nacional para la Cultura, Universidad Autónoma Metropolitana, 2016.

Marino, Daniela

"La desamortización de las tierras de los pueblos (centro de México, siglo XIX). Balance historiográfico y fuentes para su estudio", en América Latina en la historia económica. Boletin de Fuentes, 16 (2001), pp. 33-43.

"La modernidad a juicio: pleitos por la tierra y la identidad comunal en el Estado de México (municipalidad de Huixquilucan), 1856-1900", en FALcón (ed.), 2005, pp. 237-264.

"La modernidad a juicio: los pueblos de Huixquilucan en la transición jurídica (Estado de México, 1856-1911)", tesis de doctorado en historia, México, El Colegio de México, 2006.

"Lecturas posrevolucionarias de la desamortización comunal”, en Luna Argudín y Rhi Sausi (coords.), 2016, pp. 86114 .

Mendoza García, Edgar

Los bienes de comunidad y la defensa de las tierras en la Mixteca oaxaqueña. Cohesión y autonomía del municipio de Santo Domingo Tepenene, 1856-1912, México, Senado de la República, 2004.

Municipios, cofradías y tierras comunales. Los pueblos chocholtecos de Oaxaca en el siglo XIX, Oaxaca, Universidad Autónoma "Benito Juárez" de Oaxaca, Universidad Nacional Autónoma de México, Universidad Autónoma Metropolitana-Azcapotzalco, Centro de Investigaciones y Estudios Superiores en Antropología Social, 2011. 
Menegus, Margarita

"Ocoyoacac: una comunidad agraria en el siglo XIx", en Historia Mexicana, xxx:1(117) (jul.-sep. 1980), pp. 33-78.

"La venta de parcelas de común repartimiento: Toluca, 18721900”, en Menegus y Cerutti (eds.), 2001, pp. 71-90.

La Mixteca Baja entre la revolución y la reforma. Cacicazgo, territorialidad y gobierno, siglos XVIII y XIX, Oaxaca, Universidad Autónoma "Benito Juárez" de Oaxaca, Universidad Nacional Autónoma de México, 2012.

Menegus, Margarita y Mario Cerutti (eds.)

La desamortización civil en México y España (1750-1920), México, Universidad Autónoma de Nuevo León, Senado de la República, 2001.

Nueva historia

Nueva historia general de México, México, El Colegio de México, 2010.

Pérez Montesinos, Fernando

"Poised to Break: Liberalism, Land Reform, and Communities in the Purépecha Highlands of Michoacán, Mexico, 1800-1915”, tesis de doctorado en historia, Washington, D.C., Georgetown University, 2014.

SÁnchez Rodríguez, Martín

"Ixtlán: La desamortización de bienes indígenas en una comunidad michoacana y el ascenso de un arrendatario", en ZENDEJAs (coord.), 1992, pp. 91-116.

SÁnchez Silva, Carlos (coord.)

La desamortización civil en Oaxaca, Oaxaca, Universidad Autónoma “Benito Juárez” de Oaxaca, Universidad Autónoma Metropolitana, 2007. 
SCHENK, Frank

"La desamortización de las tierras comunales en el Estado de México (1856-1911). El caso del distrito de Sultepec”, en Historia Mexicana, XLv:1 (177) (jul.-sep. 1995), pp. 3-37.

"Muchas palabras, poca historia: una historiografía de la desamortización de las tierras comunales en México (1856-1911)", en Cuadernos de Historia Latinoamericana (AHILA), 7 (1999), pp. 215-227.

Zendejas, Sergio (coord.)

Estudios michoacanos IV, Zamora, El Colegio de Michoacán, 1992. 